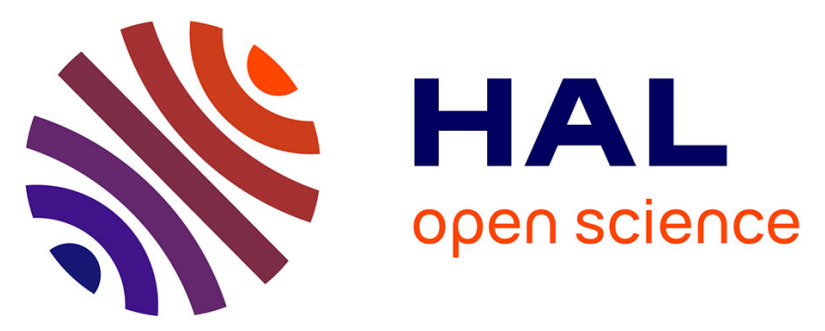

\title{
Research on Variation Rule of Sensible Heat Flux in Field Under Different Soil Moisture Content and Underlying Surface by Large Aperture Scintillometer
}

Xin Han, Qingyun Zhou, Baozhong Zhang, Di Xu

\section{- To cite this version:}

Xin Han, Qingyun Zhou, Baozhong Zhang, Di Xu. Research on Variation Rule of Sensible Heat Flux in Field Under Different Soil Moisture Content and Underlying Surface by Large Aperture Scintillometer. 10th International Conference on Computer and Computing Technologies in Agriculture (CCTA), Oct 2016, Dongying, China. pp.310-317, 10.1007/978-3-030-06155-5_31 . hal-02179971

\section{HAL Id: hal-02179971 \\ https://hal.inria.fr/hal-02179971}

Submitted on 12 Jul 2019

HAL is a multi-disciplinary open access archive for the deposit and dissemination of scientific research documents, whether they are published or not. The documents may come from teaching and research institutions in France or abroad, or from public or private research centers.
L'archive ouverte pluridisciplinaire HAL, est destinée au dépôt et à la diffusion de documents scientifiques de niveau recherche, publiés ou non, émanant des établissements d'enseignement et de recherche français ou étrangers, des laboratoires publics ou privés. 


\title{
Research on variation rule of sensible heat flux in field under different soil moisture content and underlying surface by large aperture scintillometer
}

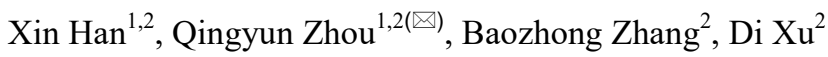 \\ ${ }^{1}$ College of Water Conservancy Engineering, Tianjin Agricultural University, Tianjin300384, China \\ \{xinhan0111@163.com, zhouqyande126.com\} \\ ${ }^{2}$ State Key Laboratory of Simulation of Water Cycle in River Basin, China Institute of Water Resources and \\ Hydropower Research, Beijing 100038, China \\ \{zhangbaozhong333@163.com, xudi@iwhr.com\}
}

\begin{abstract}
The surface sensible heat flux has a profound impact on regional energy balance of payments and regional water cycle, which is an important part of composition of the surface energy balance. This research was based on the large aperture scintillometer (LAS), combined with eddy covariance system. Sensible heat fluxes in field in September 2015 - April 2016 were observed continuously on Daxing district experimental base in Beijing. The original data was processed by BLS software and the data process cycle of large aperture scintillometer was established.The analysis of sensible heat fluxes in field under different soil moisture content and different underlying surface could provide theoretical basis for variability of sensible heat fluxes in field.
\end{abstract}

Keywords: sensible heat flux, large aperture scintillameter, eddy covariance system, soil moisture content, underlying surface.

\section{Introduction}

The surface sensible heat flux, the one significantly important part of surface energy balance, has a profound impact on regional energy balance of payments and regional water cycle, which has caused the extensive concern in the field of agriculture, meteorology, hydrology and ecology etc. At present, the primary methods of measuring the sensible heat fluxes include eddy covariance system, large aperture scintillometer, and bowen-ratio energy balance etc. Compared with other methods, large aperture scintillometer can obtain a wide range of measurement results. Bevrich and Meijininger [1] explored the feasibility of measuring the surface sensible heat fluxes using large aperture scintillometer under inhomogeneous underlying surface and rolling conditions. The results showed that large aperture scintillometer could be used to measure the surface fluxes under heterogeneous terrain condition. VonRandow [2-6] contrastively analyzed the sensible heat fluxes in the region of the Amazon middle rain forest. The results showed that the average values of large aperture scintillometer and eddy covariance system data at different time periods were different. The gap of large aperture scintillometer and eddy covariance system data was smaller when the average time was 30 mins.

This paper intended to use the observational data of large aperture scintillometer in September 2015 - April 2016 on Daxing district experimental base in Beijing to analyze the change law of sensible heat fluxes in field under different underlying surface and soil moisture content and to discuss the measured differences among different scales of sensible heat fluxes obtained by large aperture scintillometer and eddy covariance system.

\section{Experiments and Methods}

\subsection{Experimental Methods}

Directly measuring air refractive index on Daxing district experimental base used vortices relevant instrument and meteorological station. Farmland sensible heat fluxes were acquired by BLS software, which analyzing the variation regularity of sensible heat fluxes under the condition of different underlying surface and soil moisture content. 


\subsection{The principle of large aperture scintillometer and calculation method of sensible heat flux}

\subsubsection{The basic principle of large aperture scintillometer}

Large aperture scintillometer was widely used to measure the large-scale water heat fluxes under the condition of different underlying surface worldwide, which obtained a lot of research achievements [7]. LAS consist of transponder and receiving apparatus. The transmitting terminal transmits the light beam of a certain wavelength and diameter which spread in the air. The receiving terminal receives the light of the optical path. The temperature, humidity and air pressure fluctuation have a profound impact on the light beam. The air refractive index structure parameter $\mathrm{Cn}^{2}$ is used to represent the strength of the atmospheric turbulence intensity. The sensible heat flux can be calculated according to the similarity theory, supplemented by meteorological data.

The fluctuation relationship of air temperature air humidity, air pressure and air refractive index is as follows [8]:

$$
C_{n}{ }^{2}=\frac{A_{T}{ }^{2}}{T^{2}} C_{T}{ }^{2}+\frac{A_{\mathrm{q}} A_{T}}{T q} C_{T q}+\frac{A_{q}{ }^{2}}{q^{2}} C_{q}{ }^{2}
$$

Where, $C_{n}{ }^{2}$ is fT the temperature structure parameter of the refractive index; $C_{q}{ }^{2}$ is the humidity structure parameter of the refractive index; $C_{T q}$ is the covariation. Aq and $A_{T}$ respectively represent the relative contribution of $C_{q}{ }^{2}$ and $C_{T}{ }^{2}$ to $C_{n}{ }^{2}$.The sensible heat fluxes can be calculated according to the similarity theory under the condition of known value of $C_{T}{ }^{2}$.

$$
\frac{C_{T}{ }^{2}\left(Z_{L A S}-d\right)^{2 / 3}}{T_{*}^{2}}=f_{T}\left[\frac{Z_{L A S}-d}{L}\right]
$$

Where, $d$ is zero-plane displacement; $Z_{L A S}$ is the optical path height; $f_{T}$ is stability universal function; the definition of temperature scale is

$$
T_{*}=\frac{H}{\rho C_{p} \mho_{*}}
$$

Monin-Obukhov length is:

$$
L=\mathrm{u}_{*}^{2} T /\left(g k T_{*}\right)
$$

Where, $\rho$ is air density; $C_{p}$ is air specific heat at constant pressure; $k$ is karman constant; $\mathrm{u}_{*}$ is rubbing speed; $g$ is acceleration of gravity;

The sensible heat flux can be calculated through the process of iterative solution.

$$
H_{\text {free }}=0.48 \rho C_{p}\left(Z_{L A S}-d\right)(g / T)^{1 / 2}\left(C_{T}{ }^{2}\right)^{3 / 4}
$$

\subsubsection{The calculation methods and specific processes of the sensible heat flux}

(1) Download data: the time span of original data was 0:00-24:00, displaying a numerical value per minute. The document format was .dgn, including eight parts: time, standard deviation, air refractive index, extinction and the outer scale correction factor, saturation correction factor, structural parameters of air temperature, heat flux and the error code.

(2) Pretreatment of download original data: the original data could be processed as average value at different time periods, processed as average value per $30 \mathrm{~min}$ by using Datachange software, translated into format of Excel from format of .dgn.

(3) Vortices data and LAS data was arranged to the same Excel table: transform original data downloaded from eddy covariance system format by loggerNet software. 
The time span of download data from eddy covariance system was 0: 00-24:00, displaying a numerical value per $30 \mathrm{~min}$. The vortices data of average temperature, the average horizontal wind speed, atmospheric pressure, water vapor average value and air refraction coefficient from LAS data were arranged to the same Excel table.

(4) The sensible heat flux could be calculated by BLS software: input six parameters to BLS software, including installation height of LAS system, installation height of wind speed instrument, roughness, zero-plane displacement, Bowen-ratio and the distance between LAS receiving terminal and transmitting terminal. Where, $\mathrm{Z}_{0}=0.13 \mathrm{~h}, \mathrm{~h}$ is canopy height, the zero-plane displacement $\mathrm{d}=0.67 \mathrm{~h}$. $\beta$ is ratio of sensible heat and latent heat fluxes. Some parameters of the same LAS are constant. In LAS, D is $0.15 \mathrm{~m}, \lambda$ is $880 \mathrm{~nm}, \mathrm{~b}$ is $0.48, \mathrm{Cq}$ is $1005 \mathrm{JKg}^{-1} \cdot \mathrm{k}^{-1}, \mathrm{~g}$ is $9.811 \mathrm{~ms}^{-2}, \mathrm{k}$ is 0.4 . Then the sensible heat flux data can be obtained through the data of (3) Excel table.

\section{$3 \quad$ Results and Analysis}

\subsection{Sensible heat flux comparison of LAS and eddy covariance system}

In order to clarify the difference between LAS and vortices measurement data, took the average of data (8:00 to 18:00, a total of 24 points) as shown Fig.1 and Fig.2, Fig.1 showed that the change rule is same between LAS and vortices measurement data in the observation time. The values between LAS and vortices measurement data were largely different because of frequently irrigating in vortices measurement scope. So LAS measurement sensible heat fluxes data was obviously larger than vortices measurement data. Fig. 2 showed that the correlation coefficient of LAS and vortices measurement data reached at 0.5 above. The correlation was significant, which showed that LAS measurement data had high utilizability .

$\rightarrow$ LAS $\rightarrow$ EC
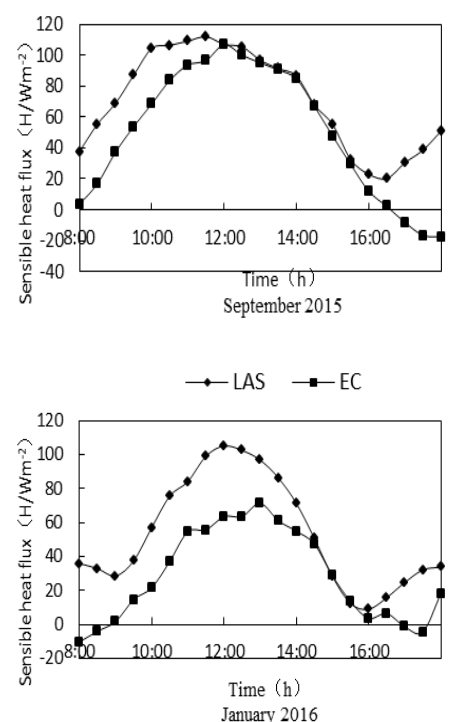

$\rightarrow$ LAS $\rightarrow$ EC

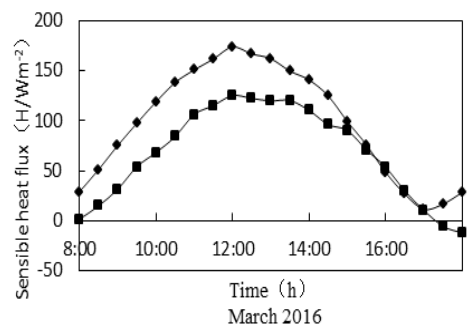

$\rightarrow$ LAS $\rightarrow$ EC
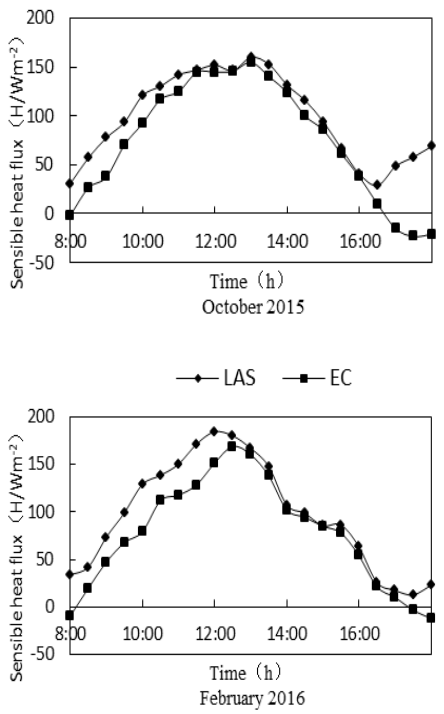

$\rightarrow$ LAS $\rightarrow$ EC

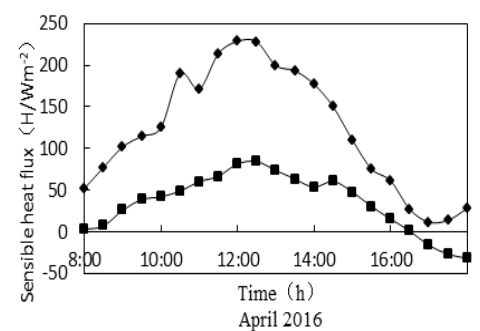

Fig.1. The test data contrast analysis diagram of LAS and eddy covariance system 

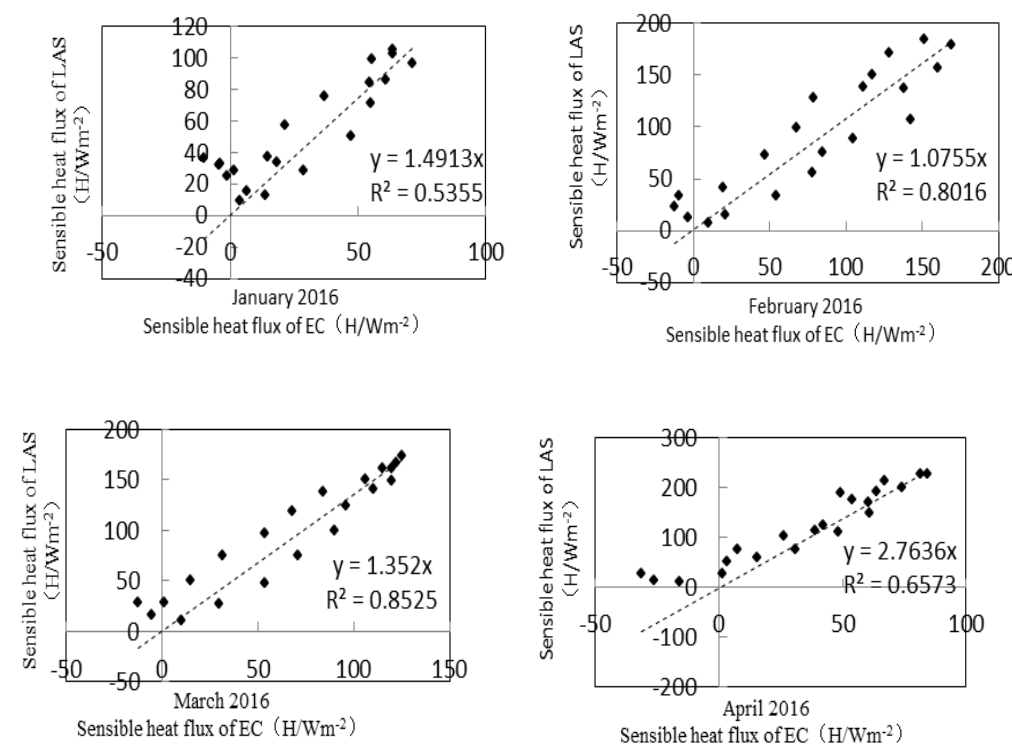

Fig. 2.The test data correlation analysis diagram of LAS and eddy covariance system

\subsection{The variation regularity of farmland sensible heat flux under different soil moisture content}

The data (the 200 points of sample average value of soil moisture content) on April 29 to March 6, 10 days of surface moisture content were selected to analyze farmland surface sensible heat fluxes. The corresponding variation regularity was shown in Fig.3.The soil moisture content was largely affected the sensible heat fluxes. The sensible heat fluxes decreased with the increase of surface soil moisture content.

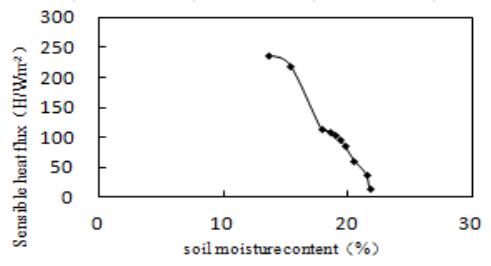

Fig.3. The sensible heat flux curve along with the change of soil moisture content

Because of irrigation at time quantum, so the variation regularity of surface sensible heat fluxes should be added to the factor of irrigation time to further illuminate the variation regularity of surface sensible heat fluxes with soil moisture content. Three irrigation time points were selected (on April 5th, May 4, May 23), this time point was used to be as a benchmark, made the trend chart of the average value of sensible heat fluxes and solar radiation at the irrigation time of before and after three days as shown in Fig.4. The results showed that the solar radiation have no change whatever before irrigation or after irrigation. The sensible heat fluxes had obviously changed under the influence of irrigation. The sensible heat flux curve before irrigation was higher than one after irrigation. The soil moisture content increased obviously after irrigation result in the decrease of the sensible heat flux, further showed the variation regularity of increase of sensible heat flux with the decrease of soil moisture content. 


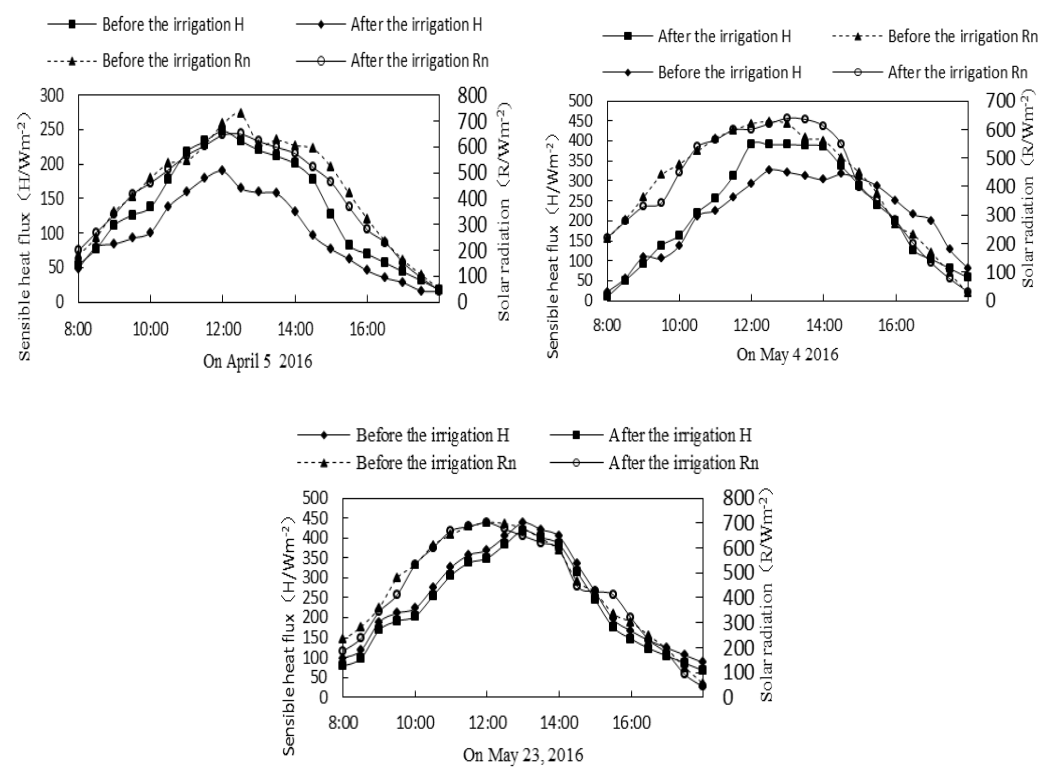

Fig.4. Sensible heat flux and solar radiation contrast variation before and after irrigation

\subsection{The variation regularity of sensible heat flux with the time under different underlying surface}

In Fig $5, \mathrm{~h}$ is the canopy height of underlying surface. The figure showed the variation regularity of farmland sensible heat flux under different canopy height of underlying surface, with selecting the data from 6:00 am to 18:00 pm. Seen from the figure, the variation tendency of farmland sensible heat flux with time is alike under three canopy height of underlying surface. They raised first then fall. The peak value occurred at about 12:00 noon.

Table 1. Sensible heat flux variation under different underlying surface

\begin{tabular}{lllll}
\hline $\begin{array}{l}\text { Underlying surface } \\
\text { canopy height }(\mathrm{h} / \mathrm{m})\end{array}$ & \multicolumn{4}{c}{ Sensible heat flux $\left(\mathrm{H} / \mathrm{Wm}^{-2}\right)$} \\
\cline { 2 - 5 } & Max & Min & Average & $\begin{array}{l}\text { Deviation } \\
\text { coefficient }\end{array}$ \\
0 & 116.94 & 18.92 & 65.74 & $46.37 \%$ \\
0.15 & 154.33 & 14.54 & 73.41 & $63.11 \%$ \\
0.455 & 228.63 & 14.06 & 113.53 & $64.61 \%$ \\
\hline
\end{tabular}

In Table 1, the underlying surface was an important factor of influencing farmland sensible heat fluxes. With the increase of the canopy height of underlying surface, the daily fluctuation of farmland sensible heat fluxes were larger and larger.

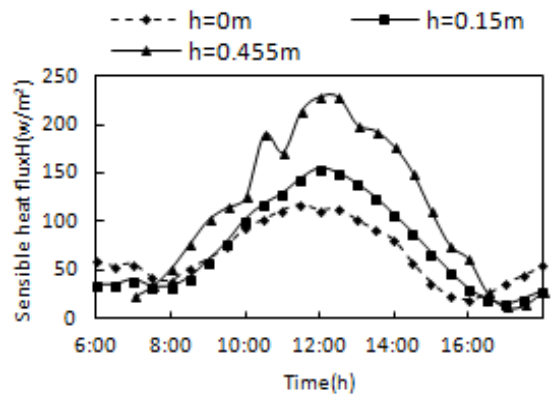

Fig. 5.Sensible heat flux average changes under the different underlying surface 
Table 2.Sensible heat flux and solar radiation under different underlying surface

\begin{tabular}{llll}
\hline $\begin{array}{l}\text { Underlying surface } \\
\text { canopy height }(\mathrm{h} / \mathrm{m})\end{array}$ & $\begin{array}{l}\text { sensible heat flux of } \\
\text { LAS }\left(\mathrm{H} / \mathrm{Wm}^{-2}\right)\end{array}$ & $\begin{array}{l}\text { Solar radiation } \\
\left(\mathrm{Rn} / \mathrm{Wm}^{-2}\right)\end{array}$ & $\begin{array}{l}\mathrm{H} / \mathrm{Rn} \\
(\%)\end{array}$ \\
\hline 0 & 65.74 & 276.33 & 23.79 \\
0.15 & 73.41 & 340.74 & 21.54 \\
0.445 & 99.5 & 482.24 & 20.63 \\
\hline
\end{tabular}

Table 2 showed the data value of the sensible heat flux and solar radiation under three canopy height of underlying surface and the proportion of surface sensible heat flux in solar radiation, generally around $20 \%$, clearly showing the proportion of surface sensible heat flux in solar radiation decrease with the increase of the canopy height of underlying surface. The maximum proportion was generally not more than $25 \%$.

\section{Conclusions}

The data variation tendency of farmland sensible heat fluxes from large aperture scintillometer and eddy covariance system were alike. There was a certain difference because of the influence of the range of observation and underlying surface, but the correlation between scintillometer and eddy covariance system was high. When the data of eddy covariance system were absent, the large aperture scintillometer to observe data could be used.

The sensible heat fluxes were different under different soil moisture content and the influence was significant. The surface sensible heat flux decreased with the increase of surface soil moisture content. The change of moisture content in a small scope will lead to large variation of the surface sensible heat flux.

The underlying surface was an important factor of affecting the surface sensible heat flux. The sensible heat fluxes were different under different underlying surface.With the increasing of the canopy height of underlying surface, the proportion of sensible heat fluxes of the solar radiation was smaller and smaller.

\section{Acknowledgment}

This work was financially supported by Governmental Public Industry Research Special Funds for Projects (201501016), the Chinese National Natural Science Fund (51609170).

\section{References}

1.Meijninger W M L, De Bruin H A R. The sensible heat fluxes over irrigated areas in western Turkey determined with a large aperture scintillometer[J]. Journal of Hydrology, 229(1): 4249(2000)

2.Von Randow C, B Kruijt, A A M Hobbslag, et al. Exploring eddy-covariance and largeaperture scintillameter measurements in an Amazonian rain forest[J]. Agricultural and Forest Meteor, 148(4): 680-690(2008).

3. De Bruin H A R, W Kohsiek, B J J M VanDenhurk. A verification of some methods to determine the fluxes of momentum sensible heat and water vapor using standard deviation and structure parameter of scalar meteorological quantities[J]. Boundary-Layer Meteorology, 63: 231-257(1993)

4. Cain J D, Rosier P T W, Meijninger W. Spatially averaged sensible heat fluxes measured over barley[J]. Agricultural and Forest Meteorology, 107: 307-322 (2001)

5. Ezzahar J, Chehbouni A, Hoedjes J C B. The use of the scintillation technique for estimating and monitoring water consumption of olive orchards in a semiarid region[J]. Agriculture Water Management, 89: 173-184(2007)

6. Bai Jie, Liu Shaomin, Lu li. Methods of dealing with, the observational data of large aperture flashing research [J]. Progress in Earth Sciences, 11(25): 1187-1196(2010)

7. Xu Ziwei, Huang Yongbin, Liu Shaomin. Study of large aperture flicker meter observation 
method[J]. Progress in Earth Sciences, 25 (11).1140-1146(2010)

8. Lu Li, Liu Shaomin, Xu Ziwei, Wang Jiemin, Li Xiaowen.Different underlying surface observational date processing analysis of large aperture flicker [J]. Progress in Earth Sciences , 20(2). 172-176(2009) 